\title{
The Oxidation of Platinum under Wet Conditions Observed by Electrochemical X-ray Photoelectron Spectroscopy
}

\author{
Rik Mom, ${ }^{*}{ }^{\dagger}$ Lorenz Frevel, ${ }^{\dagger}$ Juan-Jesús Velasco-Vélez, ${ }^{\dagger \odot}$ Milivoj Plodinec, ${ }^{\dagger, \dagger}$ Axel Knop-Gericke, ${ }^{\dagger}$ \\ and Robert Schlögl
}

${ }^{\dagger}$ Fritz-Haber-Institut der Max-Planck-Gesellschaft, Faradayweg 4-6, 14195 Berlin, Germany

${ }^{\ddagger}$ Rudjer Boskovic Institute, Bijenicka 54, 10000 Zagreb, Croatia

\section{Supporting Information}

\begin{abstract}
During the electrochemical reduction of oxygen, platinum catalysts are often (partially) oxidized. While these platinum oxides are thought to play a crucial role in fuel cell degradation, their nature remains unclear. Here, we studied the electrochemical oxidation of Pt nanoparticles using in situ XPS. When the particles were sandwiched between a graphene sheet and a proton exchange membrane that is wetted from the back, a confined electrolyte layer was formed, allowing us to probe the electrocatalyst under wet conditions. We show that the surface oxide formed at the onset of $\mathrm{Pt}$ oxidation has a mixed $\mathrm{Pt}^{\delta+} / \mathrm{Pt}^{2+} /$ $\mathrm{Pt}^{4+}$ composition. The formation of this surface oxide is suppressed when a Br-containing membrane is chosen due to adsorption of $\mathrm{Br}$ on Pt. Time-resolved measurements show that

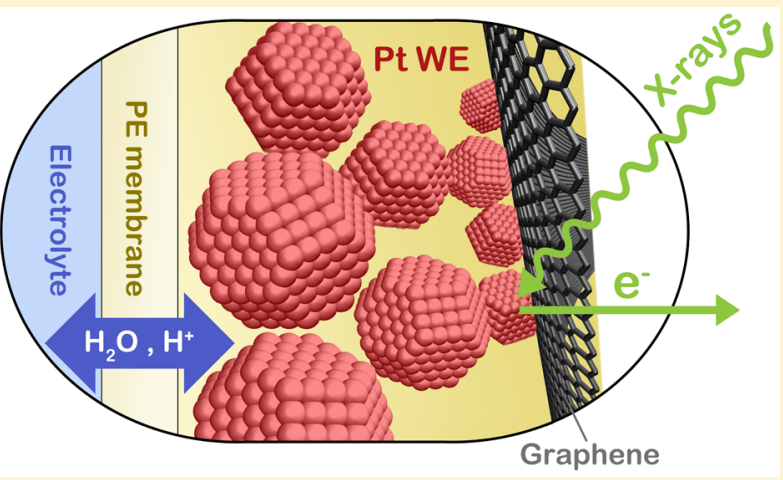
oxidation is fast for nanoparticles: even bulk $\mathrm{PtO}_{2} \cdot n \mathrm{H}_{2} \mathrm{O}$ growth occurs on the subminute time scale. The fast formation of $\mathrm{Pt}^{4+}$ species in both surface and bulk oxide form suggests that $\mathrm{Pt}^{4+}$ oxides are likely formed (or reduced) even in the transient processes that dominate Pt electrode degradation.
\end{abstract}

\section{INTRODUCTION}

Fuel cells play a central role in the transition to a sustainable society, allowing us to use the energy stored in renewable carrier molecules such as hydrogen, methanol, or ammonia. With its high efficiency, compact design and modest operating temperature, the proton exchange membrane fuel cell (PEMFC) is of particular interest. ${ }^{1}$ As a catalyst for the multielectron reactions involved in the electrochemical fuel combustion, platinum has shown unique activity. To enable widespread implementation of PEMFCs with such a scarce metal, it is essential to minimize the Pt loading. A major hurdle toward this goal is catalyst degradation, which forces engineers to use a surplus of catalyst material to ensure long device lifetime.

Under the corrosive conditions present on the cathode side of PEMFCs, where the oxygen reduction reaction (ORR) takes place, platinum is prone to dissolution. ${ }^{2}$ In particular, transient electrode potentials ${ }^{3-8}$ and the combination of low $\mathrm{pH}$ and high oxygen pressure ${ }^{3,9}$ are detrimental. The importance of oxygen in the dissolution process suggests that platinum oxides are involved. Indeed, it was shown that the surface of $\mathrm{Pt}$ cathodes is (partially) oxidized at ORR potentials, particularly in the presence of oxygen. $3,10-15$

To understand the dissolution process, it is essential to identify which oxides are formed under ORR conditions. It has been established that $\mathrm{Pt}$ oxide formation starts with surface roughening at around $1.0 \mathrm{~V}_{\mathrm{RHE}} \cdot{ }^{13,16,17}$ The roughening originates from the place exchange between $\mathrm{Pt}$ atoms in the surface and $\mathrm{O}(\mathrm{H})$ adsorbates. The surface oxide saturates at 2 monolayers of oxygen (based on the passed charge density), from which it was assumed that an $\mathrm{O}-\mathrm{Pt}-\mathrm{O}-\mathrm{Pt}$ layer is formed. ${ }^{17}$ However, the disorder in the surface structure precludes a clear assignment of the key structural elements and their oxidation state using common methods such as cyclic voltammetry, electrode mass analysis, scanning tunneling microscopy, and X-ray scattering. The onset of bulk oxidation is thermodynamically predicted around $1.0-1.2 \mathrm{~V}_{\mathrm{RHE}}{ }^{18,19}$ yet is usually observed only at significantly higher potentials due to kinetic limitations. ${ }^{17}$ A strongly hydrated and porous oxide evolves, ${ }^{17,20,21}$ which was shown to contain $\mathrm{Pt}^{4+}$ using ex situ X-ray photoelectron spectroscopy (XPS). ${ }^{21,22}$ A detailed spectroscopic characterization was precluded due to decomposition of the oxide in vacuum. ${ }^{22}$

To provide a detailed speciation of the electrochemically formed oxides on $\mathrm{Pt}$, there is a clear need for in situ X-ray spectroscopy methods, which can identify the chemical state of the disordered structures in an element-specific manner. However, spectroscopy under electrochemical conditions constitutes a major challenge, particularly for the identification of surface species. Nonetheless, hard X-ray absorption studies have been able to monitor the amount of oxidized platinum

Received: November 15, 2018

Published: March 30, 2019 

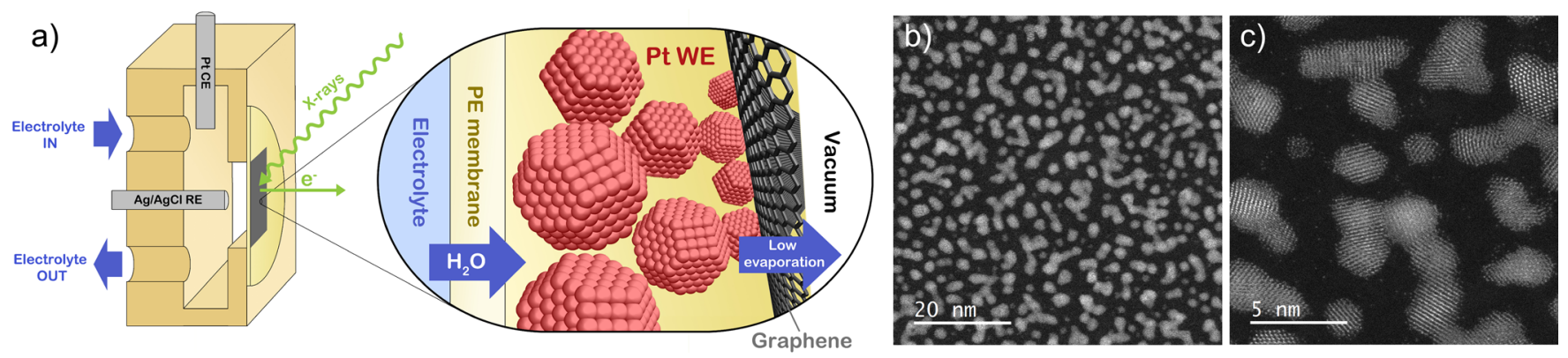

Figure 1. (a) Schematic representation of the electrochemical cell. (b) Transmission electron microscopy image of Pt nanoparticles sputtered on a Nafion film deposited on a Quantifoil TEM grid. The coverage shown here is the lowest used in this work (area coverage 37\%), equivalent to a 1 $\mathrm{nm}$ layer. (c) High-resolution image of the sample in panel $b$.
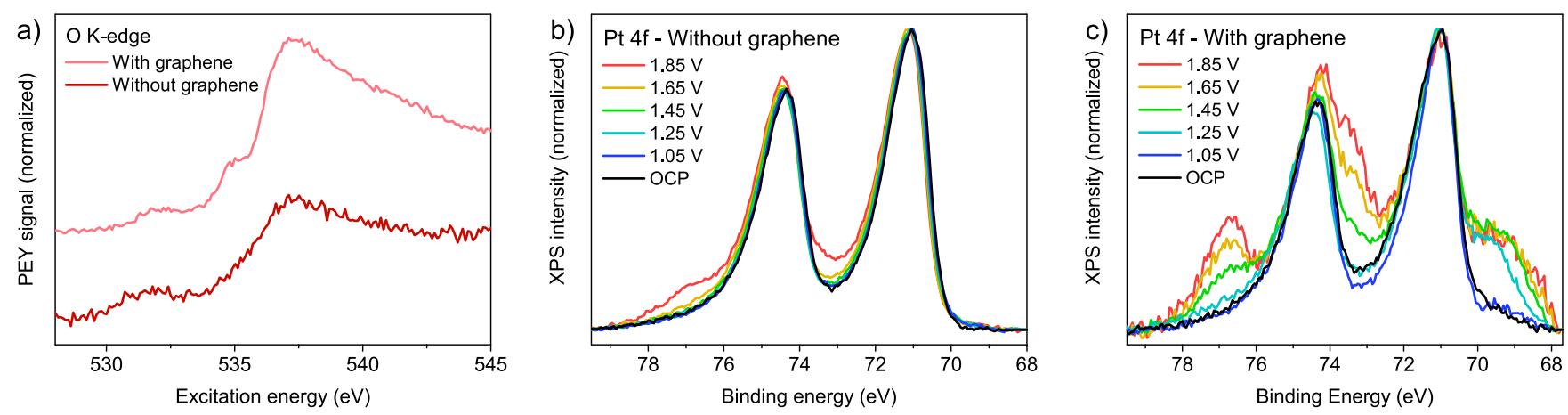

Figure 2. Effect of the graphene cover layer on electrolyte and oxidation properties of a $16 \mathrm{~nm}$ Pt layer on FAD55. (a) O K-edge spectra (PEY) recorded at open circuit potential $(0.05 \mathrm{~V})$. $(\mathrm{b}, \mathrm{c}) \mathrm{Pt} 4 \mathrm{f}$ spectra acquired during stepwise anodization of the same samples as shown in panel a, with an excitation energy of $580 \mathrm{eV}$ and $0.1 \mathrm{M} \mathrm{H}_{2} \mathrm{SO}_{4}$ electrolyte. Each potential was held at least $5 \mathrm{~min}$ prior to acquisition. Potentials are shown versus RHE.

formed on various Pt catalysts as a function of potential. ${ }^{10,14,15}$ $\mathrm{X}$-ray photoelectron spectroscopy (XPS) allows for a more surface sensitive and detailed speciation of the oxide yet faces the technical challenge of dealing with the limited escape depth of electrons in liquid. Pioneering efforts toward electrochemical XPS have been made through the study of gasphase electrochemistry on membrane-electrode assemblies, ${ }^{23-25}$ providing insight into the operation of hightemperature fuel cells. To enable studies under the more usual wet, low-temperature operation conditions, hard X-ray photoelectron spectroscopy has been employed. ${ }^{26-28}$ In another approach, the catalyst was probed through an array of microscopic graphene windows. ${ }^{29,30}$ While very promising, obtaining high-quality spectroscopy in these approaches remains challenging.

Inspired by Frevel et al., ${ }^{31}$ we combine the methods above into a graphene-capped membrane-electrode assembly in order to obtain high-quality XPS and X-ray absorption spectroscopy in the soft energy range under wet electrochemical conditions. When Pt nanoparticles are sandwiched between a back-wetted proton exchange membrane and a graphene layer, a large-area confined electrolyte layer is formed. The graphene layer serves both as an electron transparent window and as a contact to the Pt nanoparticles, allowing for a single layer of separated particles to be investigated. Using this methodology, we study the reversible oxidation of $\mathrm{Pt}^{0}$ up to $\mathrm{Pt}^{4+}$ at potentials from 0.05 to $1.85 \mathrm{~V}$ vs RHE.

\section{METHODS}

For this work, an in situ cell developed earlier ${ }^{25,32}$ has been modified with a graphene capping layer. As shown in Figure 1a, a monolayer of graphene is placed on top of the catalyst, which is supported by a proton exchange membrane. Behind the membrane is an electrolyte flow channel, which houses the $\mathrm{Ag} / \mathrm{AgCl}$ (saturated $\mathrm{KCl}$ ) reference electrode and the $\mathrm{Pt}$ counter electrode. The flow channel ensures wetting of the proton exchange membrane, which in turn leaks electrolyte to the catalyst side. The graphene capping layer provides a barrier against water evaporation from the catalyst surface into the vacuum of the ambient pressure XPS chamber. With the steady flow of water arriving to the catalyst layer through the membrane and the diminished evaporation rate from the catalyst layer due to the graphene, the partial pressure of water around the catalyst is pushed up. As will be shown in the section 3, this can lead to water condensation (see also ref 31 ), so that the catalyst can be probed under wet electrochemical conditions. As shown in previous work, ${ }^{29,30,33,34}$ the graphene layer is transparent to X-rays and electrons ( $>300 \mathrm{eV}$ kinetic energy), therefore allowing for spectroscopy to be conducted. In addition, the graphene provides electrical contact, so that isolated nanoparticles can be studied (see Figure $1 \mathrm{~b}$ ). The sample area, roughly $1 \mathrm{~mm}^{2}$, is much larger than the beam spot $(100 \mu \mathrm{m} \times 200 \mu \mathrm{m})$. Therefore, the photon flux can be used more efficiently than in previous work with microscopic graphene windows, ${ }^{29,33,34}$ facilitating high quality spectroscopy with acquisition times down to the subminute scale. Finally, we should stress that the method is robust and inexpensive and can be used in conjunction with virtually any electrocatalyst. A deeper characterization of the cell will be published elsewhere.

The Pt working electrode is sputter-deposited on the vacuum side of the membrane. As shown in Figure 1b,c, the deposition resulted in crystalline, somewhat dendritic particles. Due to this asymmetric shape, the particles are best characterized by their typical surface-tocore distance rather than their equivalent radius. Our analysis indicates surface-to-core distances in the range of 1 to $2 \mathrm{~nm}$. The catalyst loading, expressed as layer thickness, was varied between 1 and $16 \mathrm{~nm}$. Nafion 117 (Ion Power) and Fumasep FAD55 

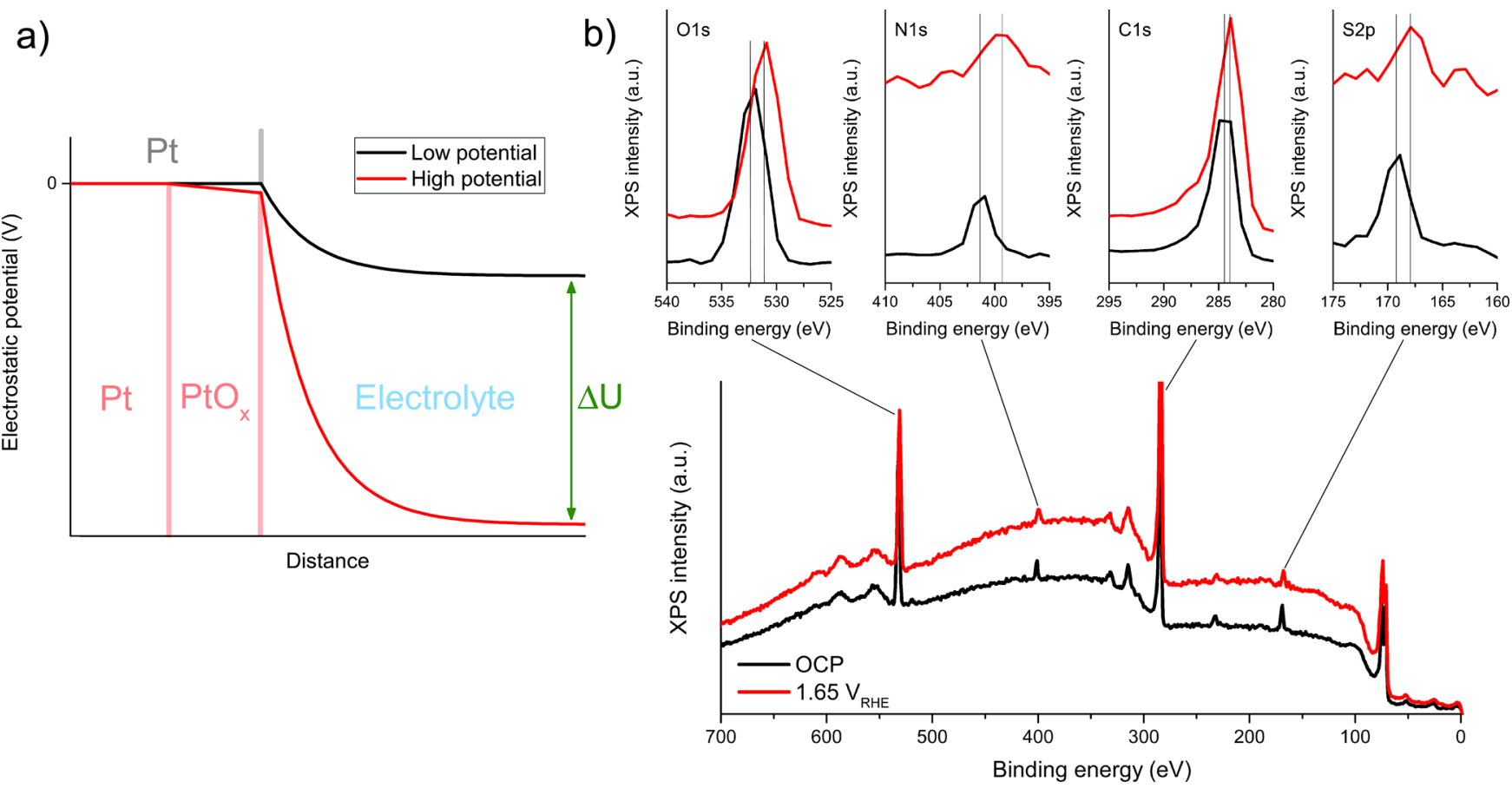

Figure 3. Influence of the local electrostatic potential on XPS peak positions. (a) Schematic representation of the electrostatic potential around the Pt particles. $\Delta U$ designates the difference in applied potential between the two depicted situations. The potential drop in the electrolyte can adopt a variety of functional forms but is shown as simple Gouy-Chapman exponential decay here. (b) Survey spectra of $16 \mathrm{~nm}$ graphene-covered Pt on FAD55 at open circuit potential $(0.05 \mathrm{~V})$ and $1.65 \mathrm{~V}$, with an excitation energy of $1100 \mathrm{eV}$ and $0.1 \mathrm{M} \mathrm{H}_{2} \mathrm{SO}_{4}$ electrolyte.

(Fumatech) were used as proton exchange membranes. For Nafion 117 , only water and protons can pass the membrane, whereas FAD55 also allows anions to diffuse to and from the working electrode. More details on the sample preparation and characterization can be found in ESI section S1.

The electrochemical cell was mounted on the near-ambient pressure XPS end station (NAPXPS1) of the ISISS beamline at the BESSY II/HZB synchrotron facility in Berlin, Germany. No gases were dosed to the cell chamber other than the leakage from the cell, leading to chamber pressures of 0.05 mbar to 0.15 mbar. For nearedge X-ray absorption fine structure (NEXAFS), electrons were collected on the analyzer nozzle to obtain the total electron yield (TEY) signal, while a partial electron yield (PEY) signal was simultaneously collected in the analyzer at a kinetic energy of $385 \mathrm{eV}$. This energy corresponds to the inelastically scattered background of the O KLL Auger peak, which combines good signal intensity with effective elimination of gas phase contributions from the PEY signal, in particular when a potential $(90 \mathrm{~V})$ is applied to the analyzer nozzle. $^{35}$ To prevent beam damage effects, each spectrum was recorded on a fresh spot on the surface. All potentials were converted to the RHE scale. Details on the analysis procedure and beam effect studies can be found in ESI sections S2 and S3, respectively.

\section{RESULTS}

As a first step, we established the degree of wetting on the $\mathrm{Pt}$ nanoparticles. Figure 2a shows O K-edge spectra for a $16 \mathrm{~nm}$ Pt layer on FAD55, with and without graphene cover layer. Both spectra are dominated by the contribution from the FAD membrane around $537.5 \mathrm{eV}$ (see Figure S7a in the ESI for blank FAD). The most notable difference is the presence of a peak at $535 \mathrm{eV}$ for the graphene-covered sample. A comparison of Figure 2a to the O K-edge spectrum of graphene deposited on gold via the same procedure indicates that this change is not due to oxygen functionalities on the graphene (see Figure $\mathrm{S} 7 \mathrm{~b}$ and its discussion in the ESI). Rather, the peak can be ascribed to the pre-edge feature of water with unsaturated hydrogen bonds. ${ }^{31,36-38}$ The relative intensity of this feature in the spectrum suggests that more than one layer of water has condensed on the catalyst, implying $100 \%$ relative humidity in the catalyst layer. Consistent with this, the $\mathrm{O} 1 \mathrm{~s}$ spectrum (Figure S8 in the ESI) shows some increase around 533-534 $\mathrm{eV}$, where multilayer $\mathrm{H}_{2} \mathrm{O}$ is expected to appear. ${ }^{36}$ Unfortunately, the many closely spaced contributions in the $\mathrm{O} 1 \mathrm{~s}$ spectra and their attenuation by graphene preclude a more detailed analysis. Nonetheless, it is clear that the graphene cover layer enables proper wetting of the Pt working electrode.

Figure $2 b, c$ shows how wetting leads to a much more pronounced electrochemical response in the Pt $4 \mathrm{f}$ spectra. While the uncovered $\mathrm{Pt}$ layer only shows minor oxidation, even at $1.85 \mathrm{~V}_{\mathrm{RHE}}$, the graphene-covered sample is clearly oxidized. The well-resolved peak at $76.7 \mathrm{eV}$ indicates that a $\mathrm{Pt}(\mathrm{IV})$ oxyhydroxide layer is formed (hereafter referred to as $\mathrm{PtO}_{2}$. $n \mathrm{H}_{2} \mathrm{O}$ ). Depth profiling (Figure S9 in the ESI) showed that the oxidation occurs at the outer surface of the electrode for the graphene-covered sample. In contrast, the uncovered sample is oxidized at the FAD55-Pt interface. These results highlight the importance of humidity for the electrochemical response in fuel cells. Indeed, it is well-documented that the power output of fuel cells is humidity-dependent. ${ }^{39,40}$ However, high humidity also leads to increased catalyst degradation. ${ }^{41,42}$ The comparison in Figure $2 b, c$ suggests that this may be related to the increased degree of oxidation under wet conditions.

Further understanding of the electrolyte can be obtained from C 1s, N 1s, O 1s, and S 2p spectra (see Figure 3). Except for the oxygen species, one does not expect significant chemical changes. However, the observed binding energy shifts $1: 1$ with the electrostatic potential of the emitting atom. This can be exploited to identify the location of various electrolyte species. As shown schematically in Figure 3a, the 

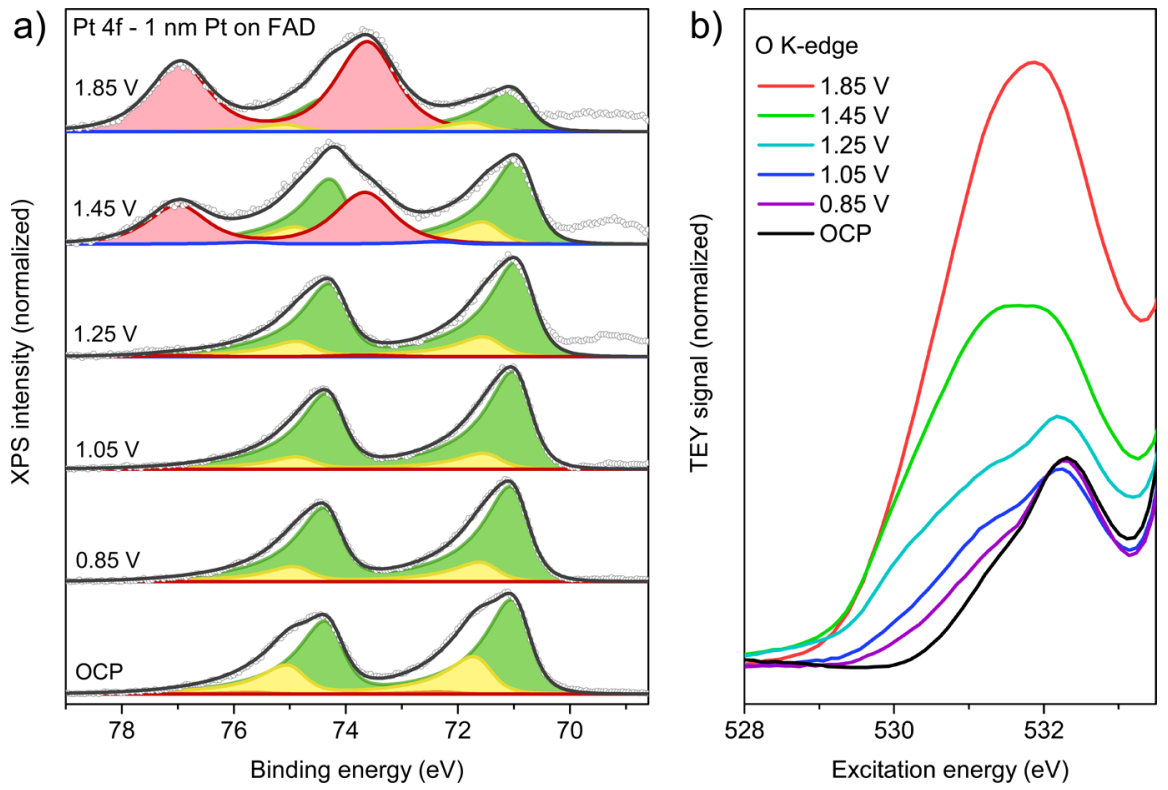

Figure 4. Stepwise anodization of graphene-covered, isolated Pt nanoparticles on FAD55 in $0.1 \mathrm{M} \mathrm{H}_{2} \mathrm{SO}_{4}$ electrolyte. (a) Pt $4 \mathrm{f}$ spectra acquired with an excitation energy of $600 \mathrm{eV}$ and fit model using $\mathrm{Pt}^{0}$ (green), $\mathrm{Pt}^{\delta+}$ (yellow), $\mathrm{Pt}^{2+}$ (blue), and $\mathrm{Pt}^{4+}$ (red) doublets. (b) The according O Kedge spectra.

electrostatic potential of the species belonging to or adsorbed on the (grounded) working electrode is zero versus the electron analyzer. If a nonconductive oxide is formed on the working electrode, a potential drop will occur in this layer. However, the constant $\mathrm{Pt}^{4+}$ peak position in Figure $2 \mathrm{c}$ suggests that this effect is negligible. In contrast, the electrostatic potential of electrolyte species will shift significantly depending on their proximity to the working electrode and the applied potential. As shown in Figure 3a, the electrostatic potential drops in the electrolyte. At the positive (anodic) potentials applied here, the electrolyte potential is negative with respect to the working electrode, leading to lower apparent binding energies.

For instance, the $\mathrm{N}$ 1s peak belonging to the FAD membrane has shifted $1.7 \mathrm{eV}$ at $1.65 \mathrm{~V}_{\mathrm{RHE}}$ with respect to open circuit potential (OCP, $0.05 \mathrm{~V}_{\mathrm{RHE}}$ ), hence close to the expected bulk electrolyte shift. In contrast, the $\mathrm{C} 1 \mathrm{~s}$ peak is shifted by only $0.5 \mathrm{eV}$, because it contains contributions from both FAD (electrolyte) and graphene (working electrode). Accordingly, the peak shape has clearly changed. Similarly, the $\mathrm{O} 1 \mathrm{~s}$ peak shows an incomplete shift of $1.2 \mathrm{eV}$ and a shape change, which can be explained as a mixed response of adsorbed water, graphene functionalities, bulk water, sulfate ions, and the FAD membrane. The $S 2 p$ peak also shows an incomplete shift $(1.3 \mathrm{eV})$ and a clear broadening, suggesting that the sulfate anions are found in both the adsorbed and free form. Finally, we note that the shoulder around $69.3 \mathrm{eV}$ in Figure $2 \mathrm{c}$ originates from $\mathrm{Br} 3 \mathrm{~d}$ electrons from the $\mathrm{FAD}$ membrane. Similar to the case of the $S 2 p$ peak, the $B r 3 d$ shoulder does not shift as a whole but rather broadens toward lower binding energy. This suggests that $\mathrm{Br}$ species can be found both as adsorbates and free electrolyte species. Thus, we identify sulfate, $\mathrm{Br}$-species, and $\mathrm{O}$-species as the adsorbates in the Pt-FAD system and the $\mathrm{N}$-functionalities and sulfate as bulk electrolyte species. An analogous analysis on Nafion is presented in Figure S10 in the ESI.

For both FAD and Nafion, we observe an intensity increase for membrane species during anodization ( $\mathrm{Br} 3 \mathrm{~d}$ peak in
Figure $2 c$ and $S 2 p$ peak in Figure S11 in the ESI), implying that the membranes redistribute within the catalyst layer. In agreement with this, the signal-to-noise ratio of the $\mathrm{Pt} 4 \mathrm{f}$ spectra decreases at elevated potential. When the potential is lowered back to $0.25 \mathrm{~V}_{\mathrm{RHE}}$, the $\mathrm{Br} 3 \mathrm{~d}$ peak disappears (not shown), yet the $\mathrm{Pt}$ signal loss is only partially reversed. This implies that some particles detach from the graphene during anodization and become completely encapsulated by the membrane. It has been suggested that the membrane redistribution occurs in order to screen the increasing electrode potential using membrane species $^{43}$ (see section S7 in the ESI for further discussion). Such a rearrangement of charged species will require solvation, which explains the absence of a rising $\mathrm{Br}$ peak in the case of a poorly wetted catalyst (Figure $2 \mathrm{~b}$ ).

Having established the general behavior of our samples, we turn our attention to the detailed evolution of the $\mathrm{Pt}$ particles during anodization. To eliminate mass and charge transport limitations in the electrolyte, we investigated low-coverage samples with isolated nanoparticles (see Figure $1 \mathrm{~b}$ ), covered with graphene. We first discuss the oxidation of Pt on FAD55. To prevent any memory effects from air exposure, the working electrode was cycled 10 times between $-0.15 \mathrm{~V}_{\mathrm{RHE}}$ and 1.25 $\mathrm{V}_{\mathrm{RHE}}$ at $50 \mathrm{mV} / \mathrm{s}$. Subsequently, the sample was anodized in steps, while recording the spectra shown in Figure 4. The data were fitted using $\mathrm{Pt}^{0}\left(\mathrm{Pt} 4 \mathrm{f}_{7 / 2}\right.$ at $\left.71.0 \mathrm{eV}\right), \mathrm{Pt}^{\delta+}(71.8 \mathrm{eV}), \mathrm{Pt}^{2+}$ $(72-72.7 \mathrm{eV})$ and $\mathrm{Pt}^{4+}(73.7 \mathrm{eV})$ doublets (details in ESI section $\mathrm{S} 2)$.

At OCP $\left(0.05 \mathrm{~V}_{\mathrm{RHE}}\right)$, a large $\mathrm{Pt}^{\delta+}$ contribution is observed. Since the OCP lies well below the oxidation potential of platinum, the $\mathrm{Pt}^{\delta+}$ peak must be adsorbate-induced. In agreement with this, hard X-ray absorption spectroscopy data $^{10,15}$ showed broadening of the Pt L-edge white line in this potential range. At higher potentials, the L-edge white line was found to sharpen. Similarly, the $\mathrm{Pt}^{\delta+}$ contribution decreases when moving to $0.85 \mathrm{~V}_{\mathrm{RHE}}$ and $1.05 \mathrm{~V}_{\mathrm{RHE}}$ in our measurements. These observations suggest a change in the adsorbate structure that reduces the adsorbate-Pt dipole. Although a 

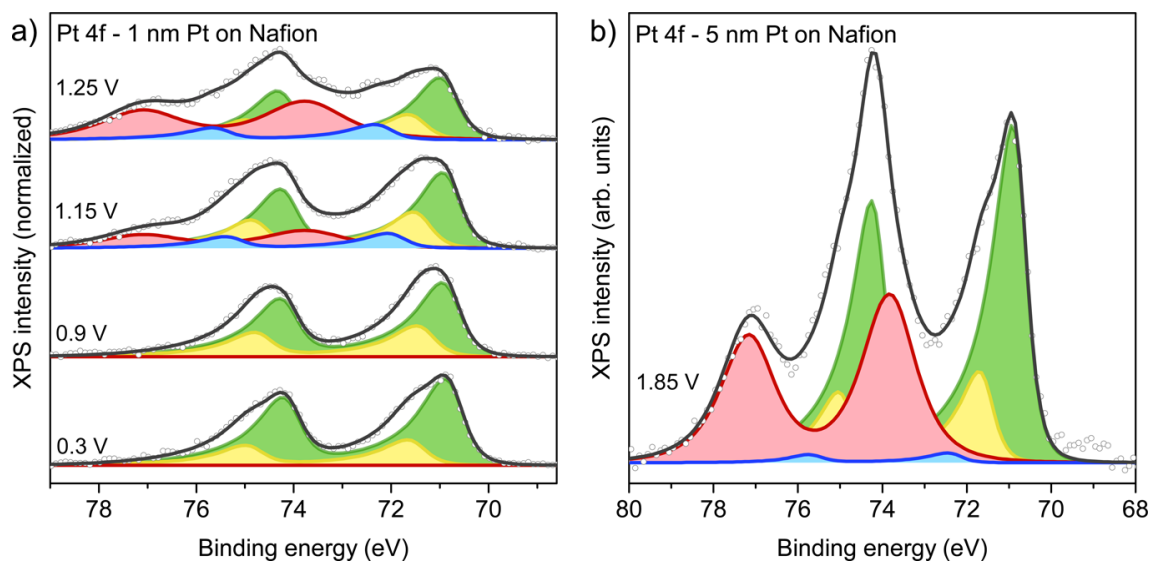

Figure 5. Pt oxidation on Nafion. (a) Stepwise oxidation of a single layer of $\mathrm{Pt}$ nanoparticles in $0.1 \mathrm{M} \mathrm{H}_{2} \mathrm{SO}_{4}$, with fit model using Pt ${ }^{0}$ (green), $\mathrm{Pt}^{\delta+}$ (yellow), $\mathrm{Pt}^{2+}$ (blue), and $\mathrm{Pt}^{4+}$ (red) doublets. Excitation energy: $480 \mathrm{eV}$. (b) Graphene-covered $4 \mathrm{~nm}$ Pt layer at $1.85 \mathrm{~V}_{\mathrm{RHE}}$ with $0.1 \mathrm{M} \mathrm{H}_{2} \mathrm{SO}_{4}$. Excitation energy: $580 \mathrm{eV}$.
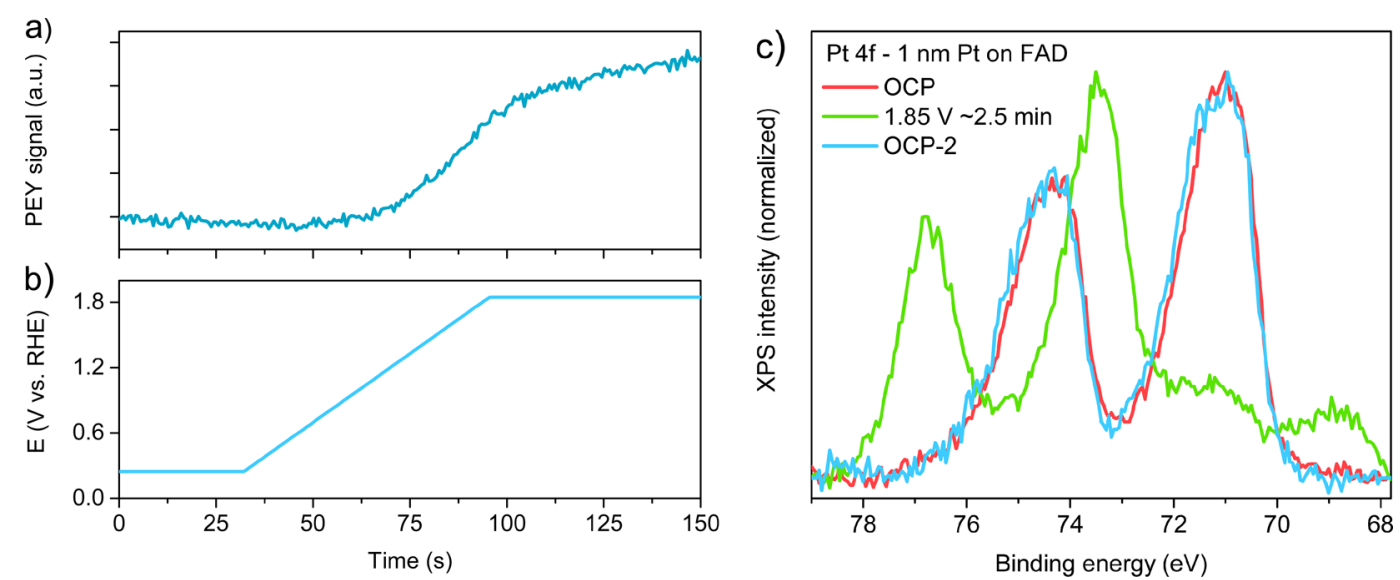

Figure 6. Kinetics and reversibility of oxide formation on graphene-covered Pt nanoparticles on FAD55 in $0.1 \mathrm{M} \mathrm{H}_{2} \mathrm{SO}_{4}$ electrolyte. (a) Development of the PEY signal at $531.8 \mathrm{eV}$ during anodization as shown in panel b. (c) Pt $4 \mathrm{f}$ spectra $(h \nu=600 \mathrm{eV})$ at $\mathrm{OCP}\left(0.05 \mathrm{~V}_{\mathrm{RHE}}\right)$ prior to the voltage sweep shown in panel $\mathrm{b}, \sim 2.5 \mathrm{~min}$ after reaching $1.85 \mathrm{~V}$, and after returning to OCP.

detailed description of these adsorbate structures is beyond our measurement capabilities at this point, one could explain this as the result of an exchange between sulfate ( 2 charges per adsorbate) and bromine species ( 1 or fewer charges per adsorbate) on the surface, or as the result of hydrogen (co)adsorption at low potentials.

The $\mathrm{O}$ K-edges up to $1.05 \mathrm{~V}_{\mathrm{RHE}}$ in Figure $4 \mathrm{~b}$ show little change with respect to OCP. This suggests that little to no adsorbed $\mathrm{O}(\mathrm{H})^{44,45}$ or surface oxide phases ${ }^{44}$ are formed, in contrast to literature for $\mathrm{H}_{2} \mathrm{SO}_{4}$ electrolytes. ${ }^{17,21}$ An explanation comes from the rise of the $\mathrm{Br} 3 \mathrm{~d}$ peak $(69.3 \mathrm{eV})$. As noted in our analysis of the electrolyte species, these $\mathrm{Br}$ species adsorb on the Pt particles. Studies on halide adsorption have shown that the $\mathrm{Pt}-\mathrm{Br}$ interaction is sufficiently strong to outcompete $\mathrm{O}(\mathrm{H})$ adsorbates, thereby thermodynamically suppressing surface oxide formation. ${ }^{8,46,47}$ At sufficiently high potential, Pt will nonetheless oxidize. Indeed, an onset of oxide formation is observed at $1.25 \mathrm{~V}$, through a minute rise in the $\mathrm{Pt}^{4+}$ component. The $\mathrm{Pt}^{4+}$ formation is accompanied by an increase in the $\mathrm{O}$ K-edge spectrum between 529.5 and $532 \mathrm{eV}$, consistent with $\mathrm{PtO}_{2} \cdot{ }^{44}$ Some contribution may come from the oxidation of the graphene cover layer, although we expect this to occur at higher potentials (see ESI section S8 and ref 31.

Further increasing the potential to $1.45 \mathrm{~V}$ induces the formation of bulk $\mathrm{PtO}_{2} \cdot n \mathrm{H}_{2} \mathrm{O}$, as evidenced by the large $\mathrm{Pt}^{4+}$ contribution and the increased $\mathrm{O}$ K-edge peak at 531.5-532 eV. Since depth profiling implies a $\mathrm{Pt}^{0}$ core, $\mathrm{Pt}^{4+}$ shell situation (see Figure S9 in the ESI), the increase in the $\mathrm{Pt}^{\delta+}$ contribution is attributed to the formation of a $\mathrm{Pt}-\mathrm{PtO}_{2} \cdot n \mathrm{H}_{2} \mathrm{O}$ interface. The $\mathrm{PtO}_{2} \cdot n \mathrm{H}_{2} \mathrm{O}$ layer grows further at $1.85 \mathrm{~V}$, almost completely consuming $\mathrm{Pt}^{0}$ (see also Figure S13 in the ESI for a $\mathrm{Pt}$ 4f spectrum recorded with higher excitation energy). Since the $\mathrm{Pt}-\mathrm{PtO}_{2} \cdot n \mathrm{H}_{2} \mathrm{O}$ interface is smaller in this situation, the $\mathrm{Pt}^{\delta+}$ component shrank along with $\mathrm{Pt}^{0}$. Similar to Figure 2, the $\mathrm{Pt}^{4+}$ peak position and shape remain constant, suggesting that there is (almost) no potential drop over the oxide layer, even for the thick oxide generated here. This implies that the hydrous $\mathrm{PtO}_{2}$ generated under electrochemical conditions is more conductive than its crystalline anhydrous counterparts. ${ }^{48}$ Consistent with this, no charging was observed during XPS studies on thick $\mathrm{PtO}_{2} \cdot n \mathrm{H}_{2} \mathrm{O}$ layers. ${ }^{21,22}$

The oxidation of $\mathrm{Pt}$ on Nafion shows striking differences to the case of Pt on FAD discussed above. Figure 5a shows the stepwise oxidation of a single layer of Nafion-supported nanoparticles. The onset potential for oxide formation lies between $0.9 \mathrm{~V}_{\mathrm{RHE}}$ and $1.15 \mathrm{~V}_{\mathrm{RHE}}$ (in agreement with the literature $\left.{ }^{10,13-19}\right)$, roughly $0.2 \mathrm{~V}$ lower than for Pt/FAD. Note that this shift in oxidation onset is also present for thicker $\mathrm{Pt}$ layers on Nafion. The initial oxidation of Nafion-supported $\mathrm{Pt}$ is evident in the $\mathrm{Pt}^{\delta+}$, the $\mathrm{Pt}^{2+}$, and the $\mathrm{Pt}^{4+}$ contributions for 

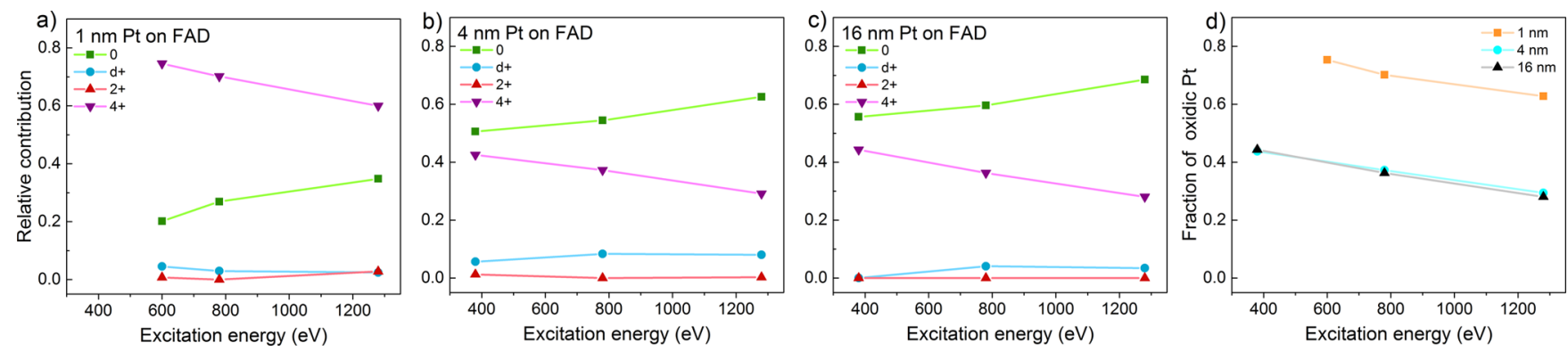

Figure 7. Depth profiling analysis of graphene-covered Pt nanoparticles/layers of various thickness on FAD55 in $0.1 \mathrm{M} \mathrm{H}_{2} \mathrm{SO}_{4}$ electrolyte, performed at $1.85 \mathrm{~V}_{\mathrm{RHE}}$ after a dwell period of at least $10 \mathrm{~min}$. For fitting procedure, see section $\mathrm{S} 2 \mathrm{in}$ the ESI. The fraction of oxidic Pt was taken as the combined $\mathrm{Pt}^{2+}$ and $\mathrm{Pt}^{4+}$ contribution to the fitted spectra.

the Nafion-supported particles, whereas $\mathrm{Pt}^{4+}$ growth was dominant for Pt/FAD. This observation shows that the $\mathrm{Pt}$ surface oxide is not uniform but rather contains $\mathrm{Pt}$ in various coordination environments, consistent with the rough surface morphology observed by X-ray scattering ${ }^{13}$ and scanning tunneling microscopy. ${ }^{16}$

At potentials where bulk oxidation can occur (i.e., 1.25 V), the $\mathrm{Pt}^{4+}$ contribution becomes increasingly dominant, finally completely replacing $\mathrm{Pt}^{2+}$ at $1.85 \mathrm{~V}$ (Figure $5 \mathrm{~b}$ ). In agreement with bulk thermodynamics, ${ }^{18}$ this shows that bulk $\mathrm{Pt}^{2+}$ oxides are unstable with respect to $\mathrm{PtO}_{2} \cdot n \mathrm{H}_{2} \mathrm{O}$ formation.

The absence of $\mathrm{Pt}^{2+}$ on our nanoparticles at high potentials differs from observations on planar bulk electrodes. ${ }^{22,26}$ This contrast can be attributed to kinetically hindered oxygen $/ \mathrm{H}_{2} \mathrm{O}$ transport in planar electrodes. Indeed, creating a few nanometers of oxide on planar Pt can require hours. ${ }^{17,26}$ In our case, the response to applied potential is much more rapid. Figure 6 a shows the evolution of the oxygen pre-edge feature of $\mathrm{PtO}_{2} \cdot n \mathrm{H}_{2} \mathrm{O}$ during anodization, monitored using the PEY signal at an excitation energy of $531.8 \mathrm{eV}$ (see ref 31 for technical details). The onset potential for oxidation is in good agreement with the static measurements from Figure $4 \mathrm{~b}$. The subsequent oxide growth nearly saturates in the following 2 min. Confirming this, a Pt 4 f spectrum recorded roughly 2.5 min after reaching $1.85 \mathrm{~V}$ shows nearly completely oxidized particles (Figure 6c). Similar to oxide formation, complete reversal to the metallic situation can be achieved in a few minutes (also for the Nafion-supported samples). Again, such reversibility was not observed for planar electrodes. ${ }^{17,22,26}$

The facile bulk oxidation of platinum is quite specific to isolated nanoparticles and is not observed for thin films. Figure 7 shows a series of depth profiling experiments performed on catalyst layers of varying thickness. Already for a layer thickness of $4 \mathrm{~nm}$, significantly less oxide is observed at $1.85 \mathrm{~V}_{\mathrm{RHE}}$. Taking into account particle size effects using Shard's method, ${ }^{49}$ we estimate that the oxide is about $1.5-2$ times thinner than for the $1 \mathrm{~nm}$ sample. Conductivity measurements on $4 \mathrm{~nm}$ samples indicate that (most of) the particles are connected into a film. Clearly, this geometric difference from the $1 \mathrm{~nm}$ sample is already sufficient to change the oxidation behavior. To exclude that the film geometry hinders electrolyte mass transport to and from the Pt surface on the graphene side, we also investigated a $16 \mathrm{~nm}$ layer, for which this effect should be more pronounced. No further decrease in the oxide thickness is observed, indicating that electrolyte transport is not a limiting factor. Rather, we explain the deeper oxidation of the isolated nanoparticles as a result of their high surface-tobulk ratio or structural flexibility, ${ }^{50}$ which facilitates easy penetration of oxygen or $\mathrm{H}_{2} \mathrm{O}$ into the particle core. Note that irrespective of the layer thickness, the oxidation kinetics were sufficient to oxidize any $\mathrm{Pt}^{2+}$ formed during the oxidation to $\mathrm{Pt}^{4+}$ (note the lack of $\mathrm{Pt}^{2+}$ in Figure 7).

Our conclusions establish a clear framework for the discussion of $\mathrm{Pt}$ dissolution. Electrochemically generated $\mathrm{Pt}$ oxides range from mixed valence $\mathrm{Pt}^{\delta+} / \mathrm{Pt}^{2+} / \mathrm{Pt}^{4+}$ surface oxide to pure $\mathrm{Pt}^{4+}$ bulk oxide (see Figure 8 ), with fast kinetics

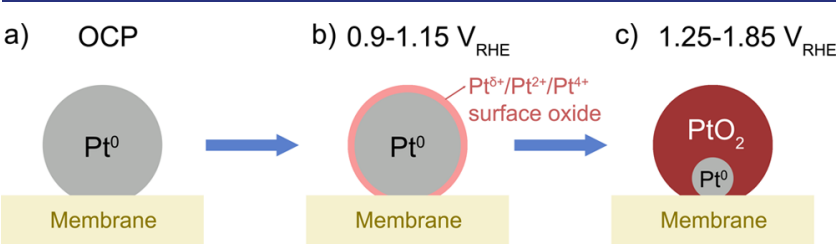

Figure 8. Schematic representation of the electrochemical oxidation of platinum. (a) Pristine metallic particles at open circuit potential. (b) Surface oxidation. This stage is absent for Pt on FAD due to Pt$\mathrm{Br}$ interaction. (c) Bulk oxidation, which finally results in pure $\mathrm{PtO}_{2}$. $n \mathrm{H}_{2} \mathrm{O}$.

connecting these oxidic states with the metallic state for nanoparticles. Transient dissolution, which dominates $\mathrm{Pt}$ electrode degradation, ${ }^{3-8}$ can therefore occur during the formation and reduction of both surface and bulk oxide, even for short excursions to oxidative potentials. To relate our results to fuel cells, we should point out that while our sample geometry (nanoparticles on Nafion) and relative humidity $(100 \%)$ are representative, we have not introduced $\mathrm{O}_{2}$ into the gas phase and our operating temperature is on the low side (23-120 ${ }^{\circ} \mathrm{C}$ for fuel cells). Since $\mathrm{O}_{2}$ is capable of oxidizing $\mathrm{Pt}$ even in the absence of applied potential, ${ }^{51}$ particularly at elevated temperature, we expect these differences to lead to a lower onset potential for oxide formation.

\section{CONCLUSION}

We have studied the electrochemical oxidation of platinum nanoparticles using in situ XPS. Pt nanoparticles were sandwiched between a proton exchange membrane and a monolayer of graphene. While electrolyte can diffuse through the membrane from the backside, graphene provides a barrier for evaporation into the vacuum chamber. The appearance of a distinct $\mathrm{H}_{2} \mathrm{O}$ peak in the $\mathrm{O} \mathrm{K}$-edge spectra indicates that this geometry results in a well-wetted environment for the catalyst nanoparticles, opening the way for the study of wet electrochemistry using XPS and electron microscopy. We show that the wetting leads to much stronger Pt oxidation at high potentials, as compared to gas phase electro-oxidation. 
Measurements conducted on a single layer of nanoparticles allowed us to probe the catalyst with minimal mass transport limitations in the electrolyte. We show that the initial oxidation of Pt on Nafion 117, between $0.9 \mathrm{~V}_{\mathrm{RHE}}$ and $1.15 \mathrm{~V}_{\mathrm{RHE}}$, yields a surface oxide with mixed $\mathrm{Pt}^{\delta+} / \mathrm{Pt}^{2+} / \mathrm{Pt}^{4+}$ oxidation state. On the alternative membrane, Fumasep FAD55, the formation of the surface oxide is suppressed due to the interaction between the $\mathrm{Pt}$ particles and $\mathrm{Br}$ species in the $\mathrm{FAD}$ membrane. For both membranes, anodization to higher potentials yields pure $\mathrm{PtO}_{2}$. $n \mathrm{H}_{2} \mathrm{O}$ (no PtO $n \mathrm{H}_{2} \mathrm{O}$ ) as thermodynamically expected. ${ }^{18}$ The oxidation on our nanoparticle catalysts is much faster than for (ultra)thin film or bulk electrodes, with significant bulk oxide growth on the subminute time-scale.

Based on these results, it is clear that the full range of $\mathrm{Pt}$ oxidation states $\left(\mathrm{Pt}^{0}-\mathrm{Pt}^{4+}\right)$ should be considered in transient dissolution phenomena, even at modest oxidation potentials and subminute time scales. For transient potential excursions to high potentials, bulk oxide is a possible precursor to dissolution.

\section{ASSOCIATED CONTENT}

\section{S Supporting Information}

The Supporting Information is available free of charge on the ACS Publications website at DOI: 10.1021/jacs.8b12284.

Details on sample preparation and characterization, details on the analysis procedure for the $\mathrm{Pt} 4 \mathrm{f}$ and $\mathrm{O} \mathrm{K}-$ edge spectra, an assessment of beam damage effects and prevention measures, $\mathrm{O} \mathrm{K}$-edge spectra of graphene on $\mathrm{Au}$, in situ $\mathrm{O}$ 1s spectra, in situ depth profiling of the oxidized Pt samples with and without graphene cover, $\mathrm{S}$ $2 \mathrm{p}$ spectra recorded during anodization experiments on $\mathrm{Pt} /$ Nafion, and a $\mathrm{Pt} 4 \mathrm{f}$ spectrum of a $\mathrm{Pt} / \mathrm{FAD}$ sample recorded at $1280 \mathrm{eV}$ excitation energy (PDF)

\section{AUTHOR INFORMATION}

\section{Corresponding Author}

*E-mail: mom@fhi-berlin.mpg.de.

\section{ORCID $\odot$}

Rik Mom: 0000-0002-5111-5591

Lorenz Frevel: 0000-0002-2622-5166

Juan-Jesús Velasco-Vélez: 0000-0002-6595-0168

\section{Notes}

The authors declare no competing financial interest.

\section{ACKNOWLEDGMENTS}

BESSY II/HZB is acknowledged for granting beam time under the proposal no. 17205966. R.M. was financially supported by the Bundesministerium furr Bildung und Forschung through the InnoEMat consortium. The authors thank Eugen Stotz, Michael Hävecker, and Detre Teschner for their help in the cell construction, beamline optimization, and graphene transfer.

\section{REFERENCES}

(1) Basualdo, M. S.; Feroldi, D. PEM Fuel Cells with Bio-Ethanol Processor Systems: A Multidisciplinary Study of Modelling, Simulation, Fault Diagnosis and Advanced Control; Springer-Verlag, 2012.

(2) Shao-Horn, Y.; Sheng, W. C.; Chen, S.; Ferreira, P. J.; Holby, E. F.; Morgan, D. Instability of Supported Platinum Nanoparticles in Low-Temperature Fuel Cells. Top. Catal. 2007, 46 (3-4), 285-305.
(3) Matsumoto, M.; Miyazaki, T.; Imai, H. Oxygen-Enhanced Dissolution of Platinum in Acidic Electrochemical Environments. J. Phys. Chem. C 2011, 115 (22), 11163-11169.

(4) Xing, L.; Jerkiewicz, G.; Beauchemin, D. Ion Exchange Chromatography Coupled to Inductively Coupled Plasma Mass Spectrometry for the Study of Pt Electro-Dissolution. Anal. Chim. Acta 2013, 785, 16-21.

(5) Furuya, Y.; Mashio, T.; Ohma, A.; Tian, M.; Kaveh, F.; Beauchemin, D.; Jerkiewicz, G. Influence of Electrolyte Composition and $\mathrm{pH}$ on Platinum Electrochemical And/or Chemical Dissolution in Aqueous Acidic Media. ACS Catal. 2015, 5 (4), 2605-2614.

(6) Topalov, A. A.; Cherevko, S.; Zeradjanin, A. R.; Meier, J. C.; Katsounaros, I.; Mayrhofer, K. J. J. Towards a Comprehensive Understanding of Platinum Dissolution in Acidic Media. Chem. Sci. 2014, 5 (2), 631-638.

(7) Cherevko, S.; Zeradjanin, A. R.; Keeley, G. P.; Mayrhofer, K. J. J. A Comparative Study on Gold and Platinum Dissolution in Acidic and Alkaline Media. J. Electrochem. Soc. 2014, 161 (12), H822-H830.

(8) Lopes, P. P.; Strmcnik, D.; Tripkovic, D.; Connell, J. G.; Stamenkovic, V.; Markovic, N. M. Relationships between Atomic Level Surface Structure and Stability/Activity of Platinum Surface Atoms in Aqueous Environments. ACS Catal. 2016, 6 (4), 25362544.

(9) Mitsushima, S.; Koizumi, Y.; Uzuka, S.; Ota, K.-I. Dissolution of Platinum in Acidic Media. Electrochim. Acta 2008, 54 (2), 455-460.

(10) Merte, L. R.; Behafarid, F.; Miller, D. J.; Friebel, D.; Cho, S.; Mbuga, F.; Sokaras, D.; Alonso-Mori, R.; Weng, T.-C.; Nordlund, D.; et al. Electrochemical Oxidation of Size-Selected Pt Nanoparticles Studied Using in Situ High-Energy-Resolution X-Ray Absorption Spectroscopy. ACS Catal. 2012, 2, 2371-2376.

(11) Kongkanand, A.; Ziegelbauer, J. M. Surface Platinum Electrooxidation in the Presence of Oxygen. J. Phys. Chem. C 2012, 116 (5), 3684-3693.

(12) Tang, L.; Han, B.; Persson, K.; Friesen, C.; He, T.; Sieradzki, K.; Ceder, G. Electrochemical Stability of Nanometer-Scale Pt Particles in Acidic Environments. J. Am. Chem. Soc. 2010, 132 (2), 596-600.

(13) Drnec, J.; Ruge, M.; Reikowski, F.; Rahn, B.; Carlà, F.; Felici, R.; Stettner, J.; Magnussen, O. M.; Harrington, D. A. Pt Oxide and Oxygen Reduction at $\mathrm{Pt}(111)$ Studied by Surface X-Ray Diffraction. Electrochem. Commun. 2017, 84, 50-52.

(14) Friebel, D.; Miller, D. J.; Nordlund, D.; Ogasawara, H.; Nilsson, A. Degradation of Bimetallic Model Electrocatalysts: An in Situ X-Ray Absorption Spectroscopy Study. Angew. Chem., Int. Ed. 2011, 50 (43), 10190-10192.

(15) Friebel, D.; Viswanathan, V.; Miller, D. J.; Anniyev, T.; Ogasawara, H.; Larsen, A. H.; O'grady, C. P.; Nørskov, J. K.; Nilsson, A. Balance of Nanostructure and Bimetallic Interactions in Pt Model Fuel Cell Catalysts: In Situ XAS and DFT Study. J. Am. Chem. Soc. 2012, 134 (23), 9664-9671.

(16) Wakisaka, M.; Asizawa, S.; Uchida, H.; Watanabe, M. In Situ STM Observation of Morphological Changes of the $\mathrm{Pt}(111)$ Electrode Surface during Potential Cycling in $10 \mathrm{mM}$ HF Solution. Phys. Chem. Chem. Phys. 2010, 12 (16), 4184-4190.

(17) Conway, B. E. Electrochemical Oxide Film Formation at Noble Metals as a Surface-Chemical Process. Prog. Surf. Sci. 1995, 49 (4), $331-452$.

(18) Jacob, T. Theoretical Investigations on the Potential-Induced Formation of Pt-Oxide Surfaces. J. Electroanal. Chem. 2007, 607 (12), $158-166$.

(19) Bard, A. J.; Parsons, R.; Jordan, J. Standard Potentials in Aqueous Solution; Dekker: New York, 1985.

(20) Zerbino, J. O.; Perdriel, C.; Arvia, A. J. Ellipsometry of Hydrous Platinum Oxide Layers and Electrodispersed Platinum Surfaces Resulting from Their Electroreduction. Thin Solid Films 1993, 232, 63-67.

(21) Peuckert, M.; Coenen, F. P.; Bonzel, H. P. XPS Study of the Electrochemical Surface Oxidation of Platinum in 1N H2SO4 Acid Electrolyte. Electrochim. Acta 1984, 29, 1305-1314. 
(22) Johnson, B.; Ranjan, C.; Greiner, M.; Arrigo, R.; Schuster, M. E.; Höpfner, B.; Gorgoi, M.; Lauermann, I.; Willinger, M.; KnopGericke, A.; et al. Characterization of Platinum and Iridium Oxyhydrate Surface Layers from Platinum and Iridium Foils. ChemSusChem 2016, 9 (13), 1634-1646.

(23) Saveleva, V. A.; Papaefthimiou, V.; Daletou, M. K.; Doh, W. H.; Ulhaq-Bouillet, C.; Diebold, M.; Zafeiratos, S.; Savinova, E. R. Operando Near Ambient Pressure XPS (NAP-XPS) Study of the Pt Electrochemical Oxidation in $\mathrm{H} 2 \mathrm{O}$ and $\mathrm{H} 2 \mathrm{O} / \mathrm{O} 2 A m b i e n t s . ~ J$. Phys. Chem. C 2016, 120 (29), 15930-15940.

(24) Casalongue, H. S.; Kaya, S.; Viswanathan, V.; Miller, D. J.; Friebel, D.; Hansen, H. A.; Nørskov, J. K.; Nilsson, A.; Ogasawara, H. Direct Observation of the Oxygenated Species during Oxygen Reduction on a Platinum Fuel Cell Cathode. Nat. Commun. 2013, 4, 2817.

(25) Arrigo, R.; Hävecker, M.; Schuster, M. E.; Ranjan, C.; Stotz, E.; Knop-gericke, A.; Schlögl, R. In Situ Study of the Gas-Phase Electrolysis of Water on Platinum by. Angew. Chem., Int. Ed. 2013, 52, 11660-11664.

(26) Favaro, M.; Valero-Vidal, C.; Eichhorn, J.; Toma, F. M.; Ross, P. N.; Yano, J.; Liu, Z.; Crumlin, E. J. Elucidating the Alkaline Oxygen Evolution Reaction Mechanism on Platinum. J. Mater. Chem. A 2017, 5 (23), 11634-11643.

(27) Takagi, Y.; Wang, H.; Uemura, Y.; Nakamura, T.; Yu, L.; Sekizawa, O.; Uruga, T.; Tada, M.; Samjeské, G.; Iwasawa, Y.; et al. In Situ Study of Oxidation States of Platinum Nanoparticles on a Polymer Electrolyte Fuel Cell Electrode by near Ambient Pressure Hard X-Ray Photoelectron Spectroscopy. Phys. Chem. Chem. Phys. 2017, 19 (8), 6013-6021.

(28) Axnanda, S.; Crumlin, E. J.; Mao, B.; Rani, S.; Chang, R.; Karlsson, P. G.; Edwards, M. O. M.; Lundqvist, M.; Moberg, R.; Ross, P.; et al. Using "tender" X-Ray Ambient Pressure X-Ray Photoelectron Spectroscopy as A Direct Probe of Solid-Liquid Interface. Sci. Rep. 2015, 5, 9788 .

(29) Velasco-velez, J. J.; Pfeifer, V.; Hävecker, M.; Weatherup, R. S.; Arrigo, R.; Chuang, C.; Stotz, E.; Weinberg, G.; Salmeron, M.; Schlögl, R.; et al. Photoelectron Spectroscopy at the Graphene Liquid Interface Reveals the Electronic Structure of an Electrodeposited Cobalt/Graphene Electrocatalyst. Angew. Chem., Int. Ed. 2015, 54, 14554-14558.

(30) Kolmakov, A.; Dikin, D. A.; Cote, L. J.; Huang, J.; Abyaneh, M. K.; Amati, M.; Gregoratti, L.; Günther, S.; Kiskinova, M. Graphene Oxide Windows for in Situ Environmental Cell Photoelectron Spectroscopy. Nat. Nanotechnol. 2011, 6 (10), 651-657.

(31) Frevel, L.; Mom, R. V.; Velasco-velez, J. J.; Plodinec, M.; KnopGericke, A.; Schlögl, R.; Jones, T. E. In Situ X-Ray Spectroscopy on the Electrochemical Development of Iridium Nanoparticles in Confined Electrolyte. J. Phys. Chem. C 2019, DOI: 10.1021/ acs.jpcc.9b00731.

(32) Pfeifer, V.; Jones, T. E.; Velasco-velez, J. J.; Arrigo, R.; Piccinin, S.; Hävecker, M.; Knop-gericke, A.; Schlögl, R. In Situ Observation of Reactive Oxygen Species Forming on Oxygen-Evolving Iridium Surfaces. Chem. Sci. 2017, 8, 2143-2149.

(33) Weatherup, R. S.; Eren, B.; Hao, Y.; Bluhm, H.; Salmeron, M. B. Graphene Membranes for Atmospheric Pressure Photoelectron Spectroscopy. J. Phys. Chem. Lett. 2016, 7 (9), 1622-1627.

(34) Velasco-velez, J. J.; Pfeifer, V.; Hävecker, M.; Wang, R.; Centeno, A.; Zurutuza, A.; Algara-Siller, G.; Stotz, E.; Skorupska, K.; Teschner, D.; et al. Atmospheric Pressure X-Ray Photoelectron Spectroscopy Apparatus: Bridging the Pressure Gap. Rev. Sci. Instrum. 2016, 87, 053121 .

(35) Hävecker, M.; Cavalleri, M.; Herbert, R.; Follath, R.; Knopgericke, A.; Hess, C.; Hermann, K.; Schlögl, R. Methodology for the Structural Characterization of VxOy Species Supported on Silica under Reaction Conditions by Means of in Situ O K-Edge X-Ray Absorption Spectroscopy. Phys. Status Solidi B 2009, 246 (7), 14591469.

(36) Nilsson, A.; Nordlund, D.; Waluyo, I.; Huang, N.; Ogasawara, H.; Kaya, S.; Bergmann, U.; Näslund, L.-Å.; Öström, H.; Wernet, P.; et al. X-Ray Absorption Spectroscopy and X-Ray Raman Scattering of Water and Ice; an Experimental View. J. Electron Spectrosc. Relat. Phenom. 2010, 177 (2-3), 99-129.

(37) Endo, O.; Nakamura, M.; Sumii, R.; Amemiya, K. 1D Hydrogen Bond Chain on $\mathrm{Pt}(211)$ Stepped Surface Observed by O K-NEXAFS Spectroscopy. J. Phys. Chem. C 2012, 116 (26), 1398013984.

(38) Bluhm, H.; Ogletree, F. D.; Fadley, C. S.; Hussain, Z.; Salmeron, M. B. The Premelting of Ice Studied with Photoelectron Spectroscopy. J. Phys.: Condens. Matter 2002, 14, L227-233.

(39) Zhang, J.; Tang, Y.; Song, C.; Xia, Z.; Li, H.; Wang, H.; Zhang, J. PEM Fuel Cell Relative Humidity (RH) and Its Effect on Performance at High Temperatures. Electrochim. Acta 2008, 53, 5315-5321.

(40) Wang, X.; Duan, Y.; Yan, W.; Weng, F. Effect of Humidity of Reactants on the Cell Performance of PEM Fuel Cells with Parallel and Interdigitated Flow Field Designs. J. Power Sources 2008, 176, 247-258.

(41) Bi, W.; Sun, Q.; Deng, Y.; Fuller, T. F. The Effect of Humidity and Oxygen Partial Pressure on Degradation of Pt/C Catalyst in PEM Fuel Cell. Electrochim. Acta 2009, 54, 1826-1833.

(42) Xu, H.; Kunz, R.; Fenton, J. M. Investigation of Platinum Oxidation in PEM Fuel Cells at Various Relative Humidities. Electrochem. Solid-State Lett. 2007, 10 (1), B1-B5.

(43) Law, Y. T.; Zafeiratos, S.; Neophytides, S. G.; Orfanidi, A.; Costa, D.; Dintzer, T.; Arrigo, R.; Knop-Gericke, A.; Schlögl, R.; Savinova, E. R. In Situ Investigation of Dissociation and Migration Phenomena at the Pt/electrolyte Interface of an Electrochemical Cell. Chem. Sci. 2015, 6 (10), 5635-5642.

(44) Miller, D. J.; Öberg, H.; Kaya, S.; Sanchez Casalongue, H.; Friebel, D.; Anniyev, T.; Ogasawara, H.; Bluhm, H.; Pettersson, L. G. M.; Nilsson, A. Oxidation of $\mathrm{Pt}(111)$ under near-Ambient Conditions. Phys. Rev. Lett. 2011, 107 (19), 195502.

(45) Schiros, T.; Näslund, L.-Å.; Andersson, K.; Gyllenpalm, J.; Karlberg, G. S.; Odelius, M.; Ogasawara, H.; Pettersson, L. G. M.; Nilsson, A. Structure and Bonding of the Water-Hydroxyl Mixed Phase on Pt(111). J. Phys. Chem. C 2007, 111 (41), 15003-15012.

(46) Markovic, N. M.; Ross, P. N., Jr. Surface Science Studies of Model Fuel Cell Electrocatalysts. Surf. Sci. Rep. 2002, 45 (4-6), 117229.

(47) Minguzzi, A.; Montagna, L.; Falqui, A.; Vertova, A.; Rondinini, S.; Ghigna, P. Dynamics of Oxide Growth on Pt Nanoparticles Electrodes in the Presence of Competing Halides by Operando Energy Dispersive X-Ray Absorption Spectroscopy. Electrochim. Acta 2018, 270, 378-386.

(48) Seriani, N.; Jin, Z.; Pompe, W.; Colombi Ciacchi, L. Density Functional Theory Study of Platinum Oxides: From Infinite Crystals to Nanoscopic Particles. Phys. Rev. B: Condens. Matter Mater. Phys. 2007, 76, 155421 .

(49) Shard, A. G. A Straightforward Method For Interpreting XPS Data From Core-Shell Nanoparticles. J. Phys. Chem. C 2012, 116, 16806-16813.

(50) An, W.; Liu, P. Size and Shape Effects of Pd@Pt Core-Shell Nanoparticles: Unique Role of Surface Contraction and Local Structural Flexibility. J. Phys. Chem. C 2013, 117, 16144-16149.

(51) Fantauzzi, D.; Krick Calderón, S.; Mueller, J. E.; Grabau, M.; Papp, C.; Steinrück, H. P.; Senftle, T. P.; van Duin, A. C. T.; Jacob, T. Growth of Stable Surface Oxides on $\mathrm{Pt}(111)$ at Near-Ambient Pressures. Angew. Chem., Int. Ed. 2017, 56 (10), 2594-2598. 